Check for updates

Cite this: RSC Adv., 2017, 7, 46109

Received 10th August 2017

Accepted 23rd September 2017

DOI: $10.1039 / \mathrm{c} 7 \mathrm{ra0} 8867 a$

rsc.li/rsc-advances

\section{Controllable synthesis of hierarchical ZSM-5 for hydroconversion of vegetable oil to aviation fuel- like hydrocarbons}

\begin{abstract}
Hao Chen, ${ }^{a}$ Xiangwen Zhang, ${ }^{\text {ac }}$ Junfeng Zhang (D) bc and Qingfa Wang (D) *ac
Hydroconversion of soybean oils to aviation fuel-like hydrocarbons was investigated over aggregated hierarchical ZSM-5 microspheres composed of small ZSM-5 nanoparticles, which were synthesized via a hydrothermal method by controlling the Si/Al ratio with carbon nanotubes (CNTs) as the template. The prepared ZSM-5 microspheres were investigated by X-ray diffraction (XRD), $\mathrm{N}_{2}$ adsorption and desorption $\left(\mathrm{N}_{2}-\mathrm{BET}\right.$ ) and scanning electron microscopy (SEM). A low Si/Al ratio resulted in small-sized seed crystals, which then grew into ZSM-5 microspheres through 3D island growth. A high Si/Al ratio resulted in the opposite growth behavior and was prone to forming well-formed individual "classic-boat" ZSM- 5 by 2D layer growth. The CNTs acted not only as a mesopore template, but also as a cage to offer suitable space making the ZSM-5 grow into the nanoparticles and form microspheres. The obtained ZSM-5 microspheres had a uniform size $(2-3 \mu \mathrm{m})$ with a hierarchical structure containing intracrystalline and intercrystalline mesopores. The spherical ZSM-5 zeolites supporting a NiMo catalyst showed high activity and selectivity toward hydroconversion of soybean oil to aviation-like biofuel $\left(C_{9}-C_{15}\right.$ hydrocarbons).
\end{abstract}

\section{Introduction}

Hydroconversion of triglycerides, the major components of vegetable oils and animals fats, to make bio-fuels has attracted considerable attention because of their alternative sources, renewability and reuse of $\mathrm{CO}_{2} \cdot{ }^{1}$ Zeolites, especially ZSM-5, are widely used as acid catalysts in the oil refining and petrochemical industries because of their intricate microporosity, high thermal stability and strong acidity. ${ }^{2-6}$ There have been thousands of papers and patents related to the synthesis, properties and utilization of ZSM-5, which has also shown excellent properties in the hydroconversion of triglycerides to produce bio-fuels. The hydrocarbon product distribution ranged from gaseous compounds to diesel, depending mainly on the type of catalyst employed with different pore structures and acid distribution. ${ }^{7,8}$

However, the sole presence of micropores in ZSM-5 limits the catalytic performance for the bulky molecules because of the intracrystalline diffusion limit, especially for the hydroconversion of vegetable oil or $\mathrm{C}_{18}$ fatty acids to aviation fuels. ${ }^{\mathbf{9}, 10}$

\footnotetext{
${ }^{a}$ Key Laboratory of Green Chemical Technology of Ministry of Education, School of Chemical Engineering and Technology, Tianjin University, Tianjin 300072, China. E-mail: qfwang@tju.edu.cn

${ }^{b}$ State Key Laboratory of Engines, School of Mechanical Engineering, Tianjin University, Tianjin 300072, China

${ }^{c}$ Collaborative Innovation Center of Chemical Science and Engineering (Tianjin), Tianjin University, Tianjin 300072, China
}

Consequently, the development of hierarchical zeolites with a secondary mesoporosity had attracted much attention due to the enhancement of accessibility to improve the catalytic activity for reactions suffering from the diffusion limitations. ${ }^{\mathbf{1 0 - 1 3}}$ Groen and Pérez-Ramírez have conducted significant contributions on the development of hierarchical zeolite obtained by alkali and acid treatment. ${ }^{14-16}$ You et al. ${ }^{17}$ examined the dehydration of D-xylose over dealuminated and desilicated H-ZSM-5 and found that the furfural selectivity increased with increasing the dealumination. Besides the post treatment, Ryoo et $a{ }^{18}$ designed bifunctional surfactants for the formation of the active and long-lived MFI zeolite with both mesopores and micropores simultaneously. The introduction of hierarchical porosity into ZSM-5 increased the proportion of light olefins in the products due to the enhancement of accessibility and diffusion. ${ }^{19}$ High specific surface hierarchical ZSM-5 was also designed and synthesized for the hydroconversion of jatropha oil to produce aviation fuel with high $i$-alkanes/n-alkanes ratio. ${ }^{20}$ Recently, the synthesized hierarchical ZSM-5 has also been used in the Fischer-Tropsch synthesis. ${ }^{\mathbf{2 1 , 2 2}}$

More recently, the zeolites with special structures have been designed for the desired catalysis reactions. For example, Bao et al. ${ }^{23}$ synthesized $\mathrm{H}$-beta/Co/ $/ \mathrm{Al}_{2} \mathrm{O}_{3}$ core-shell catalyst and found it provided a tailor-made confined reaction environment for shape selectivity. Iglesia et al. ${ }^{24}$ encapsulated Pt, Pd, Ir, Rh, and Ag clusters within NaA zeolite during hydrothermal crystallization, and the resulted catalyst was effective for the hydrogenation of alkenes and oxidative dehydrogenation of 
alkanols. Zhao et al. designed HZSM-5@SBA-15 core-shell zeolite $^{25}$ and functional ZSM-5 microspheres composed of ZSM5 nanorod and $\mathrm{Fe}_{3} \mathrm{O}_{4}$ nanoparticles, ${ }^{26}$ which showed excellent catalytic performance for methanol conversion to propylene and Fischer-Tropsch, respectively. The synthesis of zeolite materials with the tailored structures for desired functions by reproducible and flexible methods is great importance and still a significant challenge. ${ }^{26,27}$ It has been reported that the carbon templating methods can be tuned to yield either nanosized zeolite crystals or mesoporous zeolite crystals, which was the preferred alternative since this method is versatile and allows more control over the pore size distribution compared with the supramolecular templating methods. ${ }^{28}$

In this work, ZSM-5 nanoparticles with controllable shape, hierarchical structure with both micro- and mesopores and uniform size were synthesized using hydrothermal crystallization. The influence of CNTs and the Si/Al ratios on the shape evolution of ZSM-5 microspheres was investigated, and the formation mechanism of the ZSM-5 microspheres was also evaluated by X-ray diffraction (XRD), $\mathrm{N}_{2}$ adsorption and desorption $\left(\mathrm{N}_{2}\right.$-BET) and scanning electron microscope (SEM). These hierarchical ZSM-5 microsphere supported Ni and Mo catalysts were applied for the production of $\mathrm{C}_{9}-\mathrm{C}_{15}$ hydrocarbons from the hydroconversion of triglycerides.

\section{Experimental section}

\subsection{Materials}

The CNTs (outer diameter $=20-30 \mathrm{~nm}$ ) were purchased from Chengdu Organic Chemicals Co. Ltd. Conventional ZSM-5 (Con ZSM-5, Si/Al = 19) was purchased from Catalyst Plant of Nankai University. Octadecyldimethyl (3-trimethoxysilylpropyl) ammonium chloride (ODAC) (60\% methanol solution) was purchased from J\&K Scientific, China. Analytically pure tetrapropylammonium bromide (TPABr), $\mathrm{NaAlO}_{2}, \mathrm{NaOH}$ and tetraethyl orthosilicate (TEOS) were purchased from Tianjin Guangfu Fine Chemical Research Institute, China. $\left(\mathrm{NH}_{4}\right)_{6} \mathrm{Mo}_{7} \mathrm{O}_{24} \cdot 4 \mathrm{H}_{2} \mathrm{O}$ $(\geq 99.0 \mathrm{wt} \%, \mathrm{~J} \& \mathrm{~K})$ and $\mathrm{Ni}\left(\mathrm{NO}_{3}\right)_{2} \cdot 6 \mathrm{H}_{2} \mathrm{O}(\geq 98.0 \mathrm{wt} \%$, Alfa Aesar) were used as the Mo and Ni sources, respectively. The soybean oils were purchased from Wilmar International Co. Ltd. The fatty acid component of the triglycerides consisted of the $\mathrm{C}_{18}$ acid species mostly $\left(\mathrm{C}_{18: 0}\right.$, stearic acid, $\mathrm{C}_{18: 1}$, oleic acid, $\mathrm{C}_{18: 2}$, linoleic acid, $85.5 \mathrm{wt} \%)$.

\subsection{Catalyst preparations}

ZSM-5 microspheres were synthesized using TPABr and CNTs as the micropore and mesopore templates, respectively. The molar compositions of the mixtures were controlled as $x \quad \mathrm{Al}_{2} \mathrm{O}_{3} / 10$ $\mathrm{TPABr} / 10 \mathrm{Na}_{2} \mathrm{O} / 40 \mathrm{SiO}_{2} / 7,200 \mathrm{H}_{2} \mathrm{O}$, where $x$ is $1.00,0.50$ and 0.33. In a typical synthesis, 0.6/0.4/0.2 $\mathrm{g} \mathrm{NaAlO}_{2}, 8.4 \mathrm{~g} \mathrm{TPABr}$ and $2.4 \mathrm{~g} \mathrm{NaOH}$ were dissolved in $405 \mathrm{~g} \mathrm{H}_{2} \mathrm{O}$ and stirred for $12 \mathrm{~h}$. Then, $25.71 \mathrm{~g}$ TEOS was added into the resulting solution under vigorous stirring. After $12 \mathrm{~h}, 12 \mathrm{~g}$ CNTs was added to render the synthetic solutions thick. The final mixtures were transferred into an autoclave and crystallized at $175{ }^{\circ} \mathrm{C}$ for $72 \mathrm{~h}$. Then the autoclave was cooled to the room temperature. The precipitated products were filtered and washed with distilled water. The obtained samples were dried at $120{ }^{\circ} \mathrm{C}$ for $12 \mathrm{~h}$ and subsequently calcined at $600{ }^{\circ} \mathrm{C}$ in air for $24 \mathrm{~h}\left(1{ }^{\circ} \mathrm{C} \mathrm{min}^{-1}\right)$. The resulted samples were denoted ZSM-5 20, ZSM-5 40 and ZSM-5 60 , the suffix corresponded to the $\mathrm{Si} / \mathrm{Al}$ ratio.

The ZSM-5 20-O sample was synthesized under the same conditions as the ZSM-5 20 sample, except for the replacement of CNT with ODAC as the mesopore template. The molar composition of the mixture was $1 \mathrm{Al}_{2} \mathrm{O}_{3} / 10 \mathrm{TPABr} / 10 \mathrm{Na}_{2} \mathrm{O} / 40$ $\mathrm{SiO}_{2} / 4.2 \mathrm{ODAC} / 7,200 \mathrm{H}_{2} \mathrm{O}$.

$4 \mathrm{wt} \% \mathrm{Ni}$ and $12 \mathrm{wt} \%$ Mo were loaded on the ZSM-5 by incipient wetness impregnation with an aqueous solution of $\left(\mathrm{NH}_{4}\right)_{6} \mathrm{Mo}_{7} \mathrm{O}_{24}$ and $\mathrm{Ni}\left(\mathrm{NO}_{3}\right)_{2}$. After impregnation, the samples maintained at room temperature overnight and dried at $120{ }^{\circ} \mathrm{C}$ for $12 \mathrm{~h}$. Finally the samples were calcined at $450{ }^{\circ} \mathrm{C}$ for $4.5 \mathrm{~h}$.

\subsection{Catalyst characterization}

The structural properties of the hierarchical ZSM-5 samples were determined by X-ray diffraction (XRD, D/MAX-2500 X-ray diffractometer with $(\mathrm{Cu}-\mathrm{K} \alpha)$ radiation at $40 \mathrm{kV}$ and $140 \mathrm{~mA})$. Samples were measured in the $2 \theta$ range from $5^{\circ}$ to $90^{\circ}$. Elemental analysis of the $\mathrm{Si} / \mathrm{Al}$ ratio was determined by X-Ray Fluorescence (XRF, S4 Pioneer, Bruker). $\mathrm{N}_{2}$ adsorption and desorption ( $\mathrm{N}_{2}$-BET) of different samples was determined using Micromeritics Tristar (Micromeritics). Before the measurements, all the samples were degassed under vacuum at $300{ }^{\circ} \mathrm{C}$ for $4 \mathrm{~h}$. Scanning electron microscopy (SEM) images were obtained by FEI Nanosem 430 at an accelerating voltage of $0.1-30 \mathrm{kV}$.

\subsection{Catalytic experiments}

The hydroconversion of soybean oil were conducted in a fixedbed flow reactor. $4 \mathrm{~g}$ of catalysts were loaded and diluted by SiC to obtain a sufficient catalyst-bed length in the reactor. All the catalysts were crushed and sieved to 20-40 mesh fractions and pre-sulfided in situ at $320{ }^{\circ} \mathrm{C}$ and $3.0 \mathrm{MPa}$ for $4 \mathrm{~h}$ using $3.0 \mathrm{wt} \% \mathrm{CS}_{2}$ in cyclohexane under the $\mathrm{H}_{2}$ atmosphere before each reaction. Based on our previous work and literatures, all the experiments were carried out in the temperature range from 380 to $420{ }^{\circ} \mathrm{C}$ for these zeolite supported catalysts.

The products of each experiment were collected for $4 \mathrm{~h}$ under the given conditions. The organic liquid products were qualitatively determined via gas chromatography/mass spectroscopy (GC/MS) (Agilent Model 6890N gas chromatograph, coupled with an Agilent Model 5975N mass spectrometer). A gas chromatograph (Agilent, Model 7890A), equipped with a flame ionization detector (FID) and a commercially column (PONA, $50 \mathrm{~m} \times 0.20 \mathrm{~mm} \times 0.5 \mu \mathrm{m}$ ), was used to quantitatively analyze the hydrocarbons using tetracosane as the internal standard. The following program was used for the analysis of organic liquid products: initial temperature $40{ }^{\circ} \mathrm{C}$ (holding $3 \mathrm{~min}$ ), heating first at $3^{\circ} \mathrm{C} \mathrm{min}^{-1}$ to $100{ }^{\circ} \mathrm{C}$, then $20{ }^{\circ} \mathrm{C} \mathrm{min}^{-1}$ to $250{ }^{\circ} \mathrm{C}$ and finally at $5^{\circ} \mathrm{C} \mathrm{min}^{-1}$ to $290^{\circ} \mathrm{C}$ with dwelling time of $16 \mathrm{~min}$. The effect of solvent on the product distribution was identified by a preliminary experiment using the solvent cyclohexane as the reactant. All measurements were repeated three times under 
the same conditions to check the reproducibility of the data and average values were used. Then the conversion and selectivity were calculated according to eqn (1) and (2):

$$
\text { Conversion }=\left(m_{\text {SO feed }}-m_{\text {SO products }}\right) / m_{\text {SO feed }}
$$

$$
\text { Selectivity }\left(\mathrm{C}_{x} \mathrm{H}_{y}\right)=(\mathrm{CH})_{n} \text { products } / \sum\left((\mathrm{CH})_{n} \text { products }\right)
$$

where $m_{\mathrm{SO} \text { feed }}$ and $m_{\mathrm{SO} \text { products }}$ are the weights of soybean oil in the feed and in the products, respectively. $(\mathrm{CH})_{n}$ products is the weight of $\mathrm{C}_{n}$ hydrocarbons in the products.

\section{Results and discussion}

\subsection{Textural structure of hierarchical ZSM-5 zeolites}

The XRD patterns of the ZSM-5 samples prepared with different $\mathrm{Si} / \mathrm{Al}$ molar ratios are shown in Fig. 1. All the hierarchical ZSM-5 samples showed similar characteristic peaks in the range of 6$9^{\circ}$ and $22.5-25.0^{\circ}$, indicating the MFI structure of ZSM- 5 zeolite. The relative crystallinity was determined based on the intensity of the characteristic peaks in the range between $6-9^{\circ}$ and $22.5-$ $25.0^{\circ}$. The relative crystallinity declined sharply for the ZSM- 540 (20\%) and ZSM-5 20 (16\%) samples and much more for ZSM-5 20-O (9\%). The samples, which were synthesized with a Si/Al ratio of 20 and 40 showed the appearance of large intensity peak at $2 \theta=26.6^{\circ}$, which attributed to the crystalline phase of $\mathrm{SiO}_{2}$ (i.e. quartz) ${ }^{29}$ indicating the beginning of the formation of new phase. ${ }^{29}$ The $\mathrm{N}_{2}$ adsorption and desorption isotherms (Fig. 2) showed the type IV isotherms with a steep increase at relative pressure $P / P_{0}<0.02$ and a hysteresis loop at a relative pressure $P / P_{0}$ of $0.2-1.0$, suggesting the presence of both micropores and mesopores, ${ }^{30}$ which was further proved by the pore size distribution of mesopores as shown in Fig. 2. It was found that the mesopore size distributions of the ZSM-5 20, ZSM-5 40 and ZSM-5 60 were all centred at $30 \mathrm{~nm}$ because of the CNTs (outer diameter $=20-30 \mathrm{~nm}$ ) used as mesopore template. The mesopores were formed after removing the CNTs. The parallel disposition of the adsorption and desorption branches suggested an open mesoporous structure interconnected with the outer surface. ${ }^{15}$ Table 1 shows the physical properties of the series ZSM-5 zeolites. The ZSM-5 20 and ZSM-5 40 samples had the same distribution of surface area with very little mesopore surface area. This was because the mesopores in ZSM-5 20 and ZSM-5 40 samples were composed of intercrystalline and intracrystalline mesopores, mainly the intercrystalline mesopores. While the mesopores in ZSM-5 60 sample were mainly from the intracrystalline mesopores, which was further proved by SEM images as shown Fig. 3c, which clearly showed the mesopores in the framework of ZSM-5.

The SEM images of the ZSM-5 20, ZSM-5 40 and ZSM-5 60 samples are shown in Fig. 3. All the samples showed the uniform size in the range of $2-4 \mu \mathrm{m}$. Spherical morphologies for the ZSM-5 20 sample, sphere-like for the ZSM-5 40 sample and "classic-boat" morphology for the ZSM-5 60 sample could be clearly observed. Moreover, the spherical surfaces of the ZSM-5 20 and ZSM- 540 samples were composed of many small nanosized ZSM-5 particles. Therefore, the ZSM-5 microspheres had a hierarchical structure with both intracrystalline and intercrystalline mesopores. The SEM image of the ZSM-5 60 sample showed an open mesoporous structure interconnected with the outer surface, which was consistent with the result of $\mathrm{N}_{2}$ adsorption and desorption. And the size of the mesopores (20$50 \mathrm{~nm}$ ) were well consistent with the diameter of CNTs.

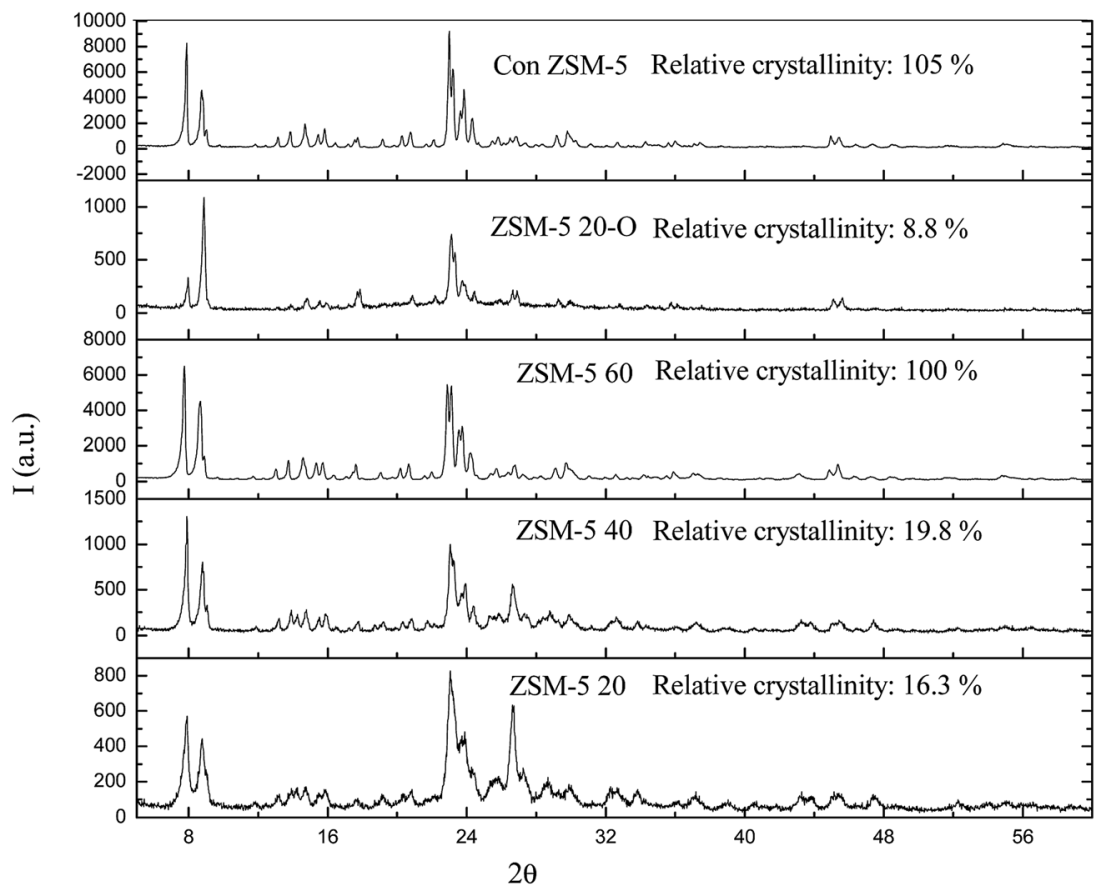

Fig. 1 XRD pattern of the hierarchical ZSM-5 samples. 

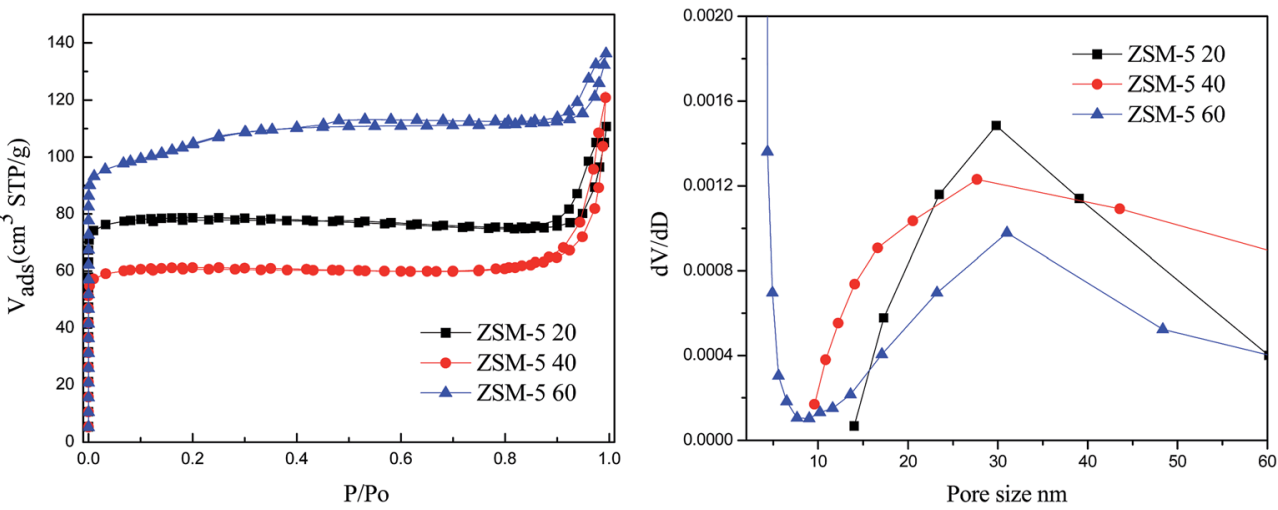

Fig. $2 \mathrm{~N}_{2}$-BET isotherms and mesopore size distributions of the ZSM-5 20, ZSM-5 40 and ZSM-5 60 zeolites.

Table 1 Physical properties of the series ZSM-5

\begin{tabular}{lllll}
\hline & $S_{\text {BET }}{ }^{a}\left(\mathrm{~m}^{2} \mathrm{~g}^{-1}\right)$ & $S_{\text {micro }}\left(\mathrm{m}^{2} \mathrm{~g}^{-1}\right)$ & $S_{\text {ext } / \mathrm{mes}\left(\mathrm{m}^{2} \mathrm{~g}^{-1}\right)}$ & $V_{\text {total }}^{b}\left(\mathrm{~cm}^{3} \mathrm{~g}^{-1}\right)$ \\
\hline Con ZSM-5 & 335 & 298 & 37 & 0.1850 \\
ZSM-5 20 & 261 & 249 & 12 & 0.1712 \\
ZSM-5 40 & 203 & 192 & 11 & 0.1870 \\
ZSM-5 60 & 369 & 209 & 160 & 0.1190
\end{tabular}

${ }^{a}$ Specific surface area. ${ }^{b}$ Pore volume.
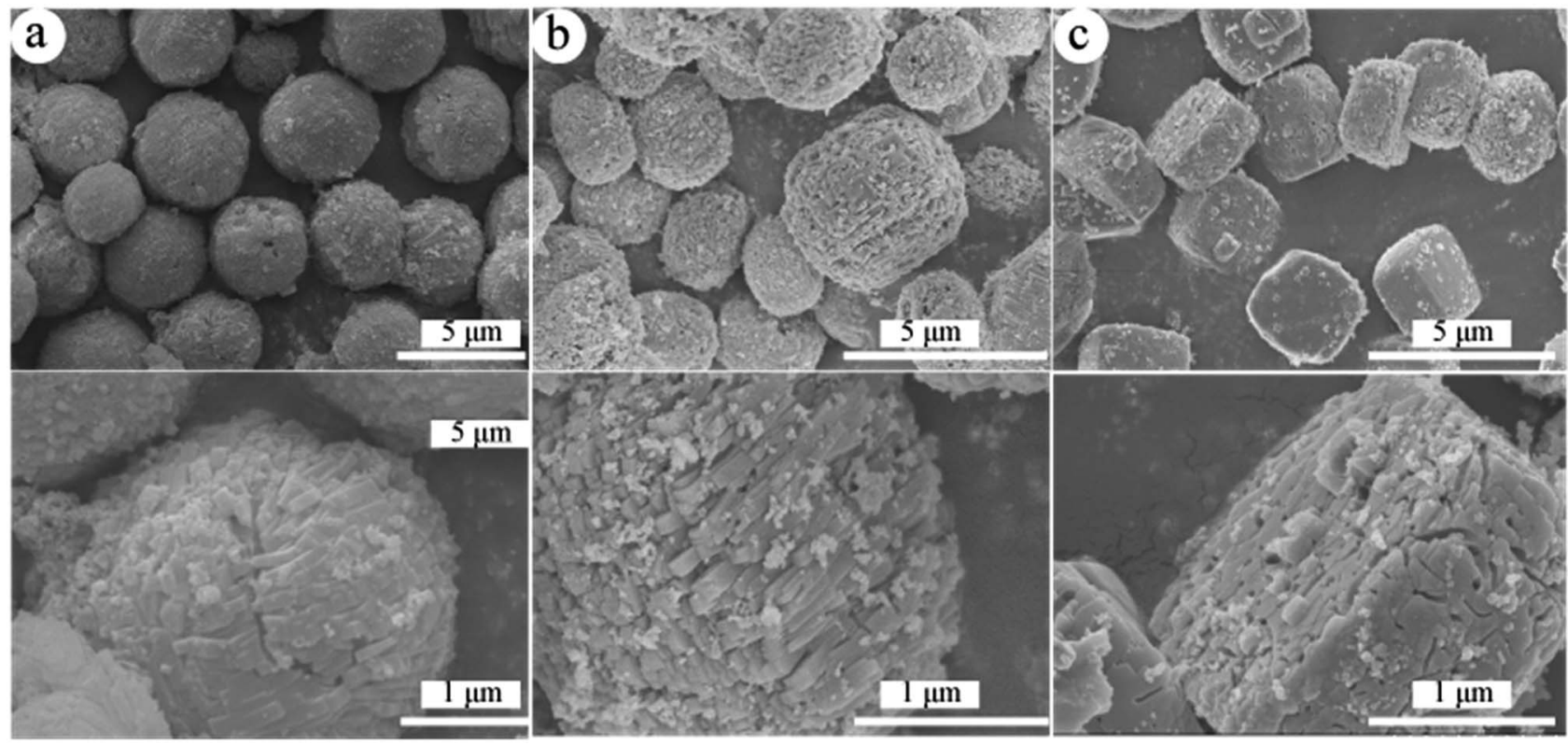

Fig. 3 SEM images of obtained hierarchical ZSM-5 samples. (a) ZSM-5 20, (b) ZSM-5 40 and (c) ZSM-5 60.

\subsection{Formation of ZSM-5 microspheres}

Zhao et al. ${ }^{26}$ reported that the magnetic $\mathrm{Fe}_{3} \mathrm{O}_{4}$ @ $\mathrm{ZSM}-5$ microspheres was formed via $\mathrm{Fe}_{3} \mathrm{O}_{4}$-assisted surface recrystallization, and the alkalinity was very crucial for the formation of microspheres. In our work, the ZSM-5 microsphere was also formed without magnetic $\mathrm{Fe}_{3} \mathrm{O}_{4}$ nanoparticle, instead, by using CNTs template. Moreover, it could be observed that the morphologies of the ZSM-5 20 and 40 samples in Fig. 3a and b were obviously different. Therefore, the addition of CNTs and the control of $\mathrm{Si} / \mathrm{Al}$ ratio played significant roles on the shape evolution of the hierarchial ZSM-5 zeolite.

3.2.1 Effect of $\mathrm{Si} / \mathrm{Al}$ ratio. To elucidate the formation of the ZSM-5 microspheres in our system, we carried out three different $\mathrm{Si} / \mathrm{Al}$ ratios $(\mathrm{Si} / \mathrm{Al}=20,40,60)$ to synthesize the ZSM-5 zeolite (see Table 2). The morphology of the ZSM-5 samples 
Table 2 Reactant compositions for synthesized ZSM-5 zeolites with different Si/Al molar ratios

\begin{tabular}{lll}
\hline Sample & Gel compositions (mol) $\mathrm{Al}_{2} \mathrm{O}_{3}: \mathrm{TPABr}: \mathrm{Na}_{2} \mathrm{O}: \mathrm{SiO}_{2}: \mathrm{H}_{2} \mathrm{O}$ & $\mathrm{Si}^{\mathrm{Al}}{ }^{a} \mathrm{molar}_{\mathrm{ratio}}$ \\
\hline ZSM-5 20 & $1.00: 10: 10: 40: 7200$ & 25.5 \\
ZSM-5 40 & $0.50: 10: 10: 40: 7200$ & 44.8 \\
ZSM-5 60 & $0.33: 10: 10: 40: 7200$ & 66.5 \\
${ }^{a}$ Determined by XRF. & &
\end{tabular}

exhibited significant changes as the $\mathrm{Si} / \mathrm{Al}$ ratio increased to 60 . No microspheres were observed except for individual "classicboat" one-by-one particles, indicating that the $\mathrm{Si} / \mathrm{Al}$ ratio had a strong influence on the growth of ZSM-5 zeolite. In an Alenriched system, the individual ZSM-5 nanoparticles would stepwise aggregate to form condensed aggregates and high intergrowth and twinning. ${ }^{31,32}$ Thus, the growth and crystal size of ZSM- 5 was tailored by controlling the $\mathrm{Si} / \mathrm{Al}$ ratio.

3.2.2 Effect of CNTs. The role of CNTs in the ZSM-5 crystallization process was also investigated by replacing the CNT with a conventional organic mesopore directing agent, octadecyldimethyl (3-trimethoxysilylpropyl) ammonium chloride (ODAC). As shown in Fig. 4, the aggregated ZSM-5 microsphere disappeared, and the crystal size of the resulting ZSM-5 20-O sample was larger than that of the ZSM-5 20 sample. The ZSM-5 20-O sample was synthesized using the same molar compositions and the pore-directing agents (TPABr and ODAC) as the reported work. ${ }^{20}$ Thus, the size distribution of mesopores in ZSM-5 20-O sample was also centered at 20-30 nm, which was similiar with that of ZSM-5 20, 40 and 60 samples. Fig. $4 \mathrm{~b}$ showed the morphology of ZSM-5 20 sample before calcination. It was observed that some CNTs embedded into the ZSM-5 microspheres clearly. After calcination, the thermolysis of CNTs formed the intracrystalline mesopore structure which was not found in the ZSM-5 20-O sample. In addition, the ZSM-5 20 sample were encapsulated in the net formed by CNTs, indicating that the CNTs was a significant size controller for the synthesis of ZSM-5 microspheres. This result suggested that the CNTs acted like a size controlled cage limiting the anisotropic growth of ZSM-5 crystal in a confined space and favoring seed crystal aggregation to form the uniform ZSM-5 microspheres (see Fig. 3). Replacing CNTs with the organic soft template ODAC, the ZSM-5 nanocrystal was prone to anisotropic growth to form the classic-boat morphology with one-by-one large particle.

The ZSM-5 samples at different crystallization intervals were collected to further elucidate the formation of ZSM-5 microspheres in CNTs cage. The SEM images of all the collected samples are shown in Fig. 5. Fig. 5a showed the typical morphology of amorphous aluminosilicate gel before crystallization treatment at $175{ }^{\circ} \mathrm{C}$ in an autoclave. After $2 \mathrm{~h}$ hydrothermal crystallization treatment at $175^{\circ} \mathrm{C}$, as shown in Fig. $5 \mathrm{~b}$, the precursor crystals were formed surrounded by CNTs. These precursors crystals gradually aggregated and grew in the confined space and underwent further into aggregated zeolite particles (Fig. 5c-g). It has been reported that high hydrothermal temperature would lead to fast crystallization of ZSM-5 nanocrystals. ${ }^{26}$ Therefore, the precursor particles grew fast in the CNTs environment from $0.9 \mu \mathrm{m}$ at $2 \mathrm{~h}$ to $c a .3 \mu \mathrm{m}$ at $6 \mathrm{~h}$ under high temperature $\left(175^{\circ} \mathrm{C}\right)$ (Fig. $5 \mathrm{c}$ ), which might also promote the aggregation of the precursor crystals. It seemed that the samples were composed of sphere-like species with a uniform size of $2-3 \mu \mathrm{m}$. On its surface, some rectangular sharp edges were observed, which was also reported by Zhao, ${ }^{26}$ implying the component of aggregated ZSM- 5 crystals. After $6 \mathrm{~h}$ hydrothermal treatment, the aggregate size seemed not to change any more (Fig. $5 \mathrm{f}$ and $\mathrm{g}$ ). But the microsphere gradually became perfect. Thus, for the Al-enriched gel composition, the seed crystals grew into a small size and aggregated during crystallization. Then, the formed seed crystals continued growing in the CNTs cage to synthesize the ZSM-5 microspheres.
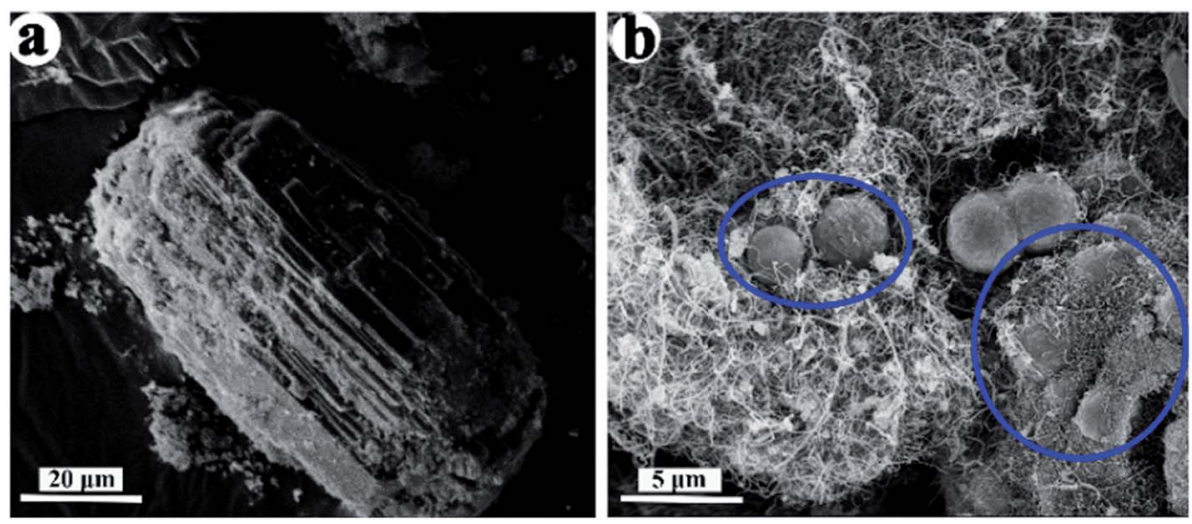

Fig. 4 SEM images of (a) ZSM-5 20 using ODCA as template and (b) ZSM-5 20 with CNT template before calcination. 

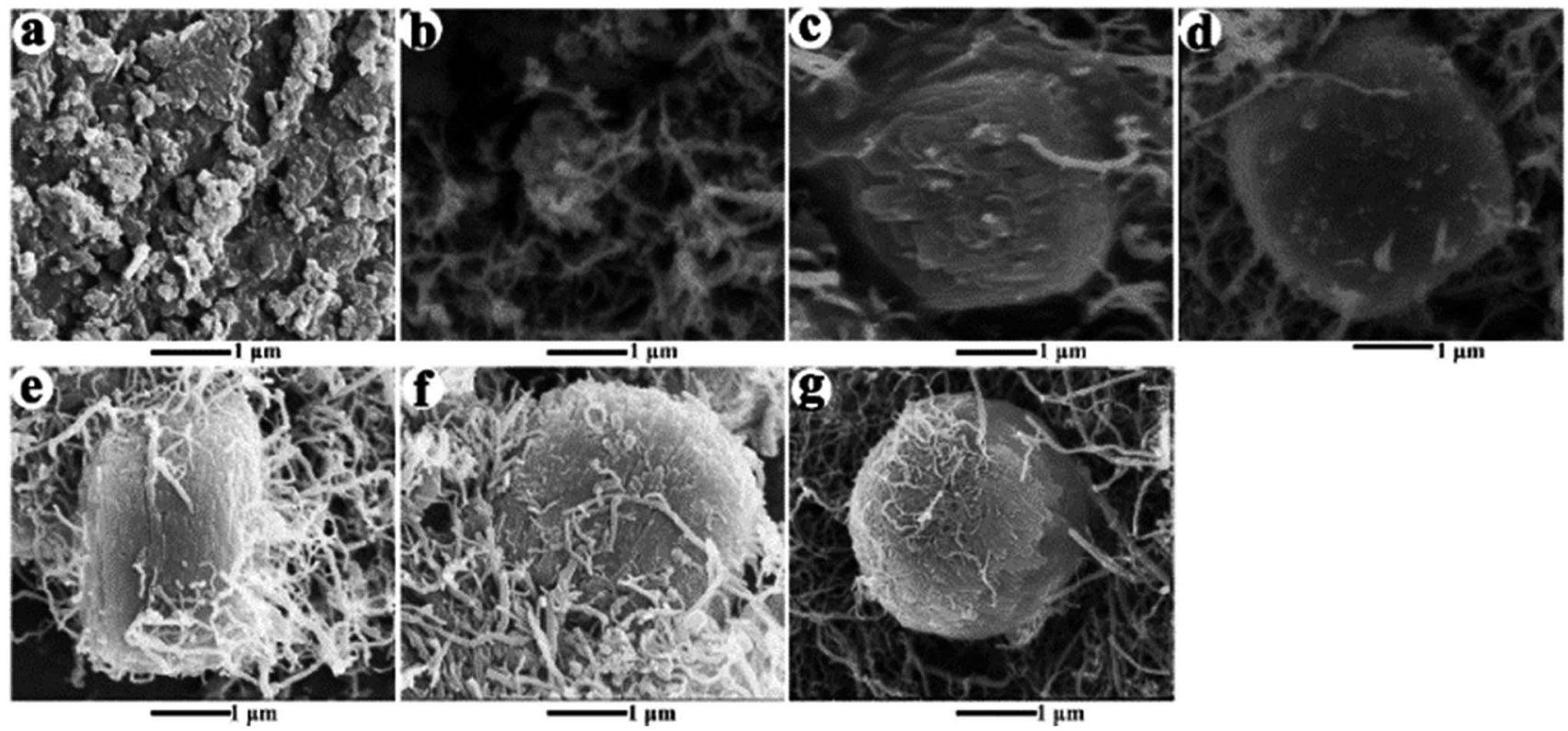

Fig. 5 SEM images of the samples obtained at different reaction time. ((a) $t_{\mathrm{c}}=0 \mathrm{~h}$, (b) $t_{\mathrm{c}}=2 \mathrm{~h},(\mathrm{c}) t_{\mathrm{c}}=6 \mathrm{~h},(\mathrm{~d}) t_{\mathrm{c}}=8 \mathrm{~h},(\mathrm{e}) t_{\mathrm{c}}=18 \mathrm{~h}$, (f) $t_{\mathrm{c}}=24 \mathrm{~h},(\mathrm{~g})$ $\left.t_{\mathrm{c}}=72 \mathrm{~h}\right)$

Generally, the MFI zeolite crystallization was reported containing two-steps: nucleation and crystal growth. Convectional mechanisms involved 2D layer nucleation and spreading, forming well-fined faceted crystal structure. Recently, Lupulescu and Rimer $^{33}$ found that the growth mechanism of MFI zeolite was juxtaposed between classical models (2D layer growth) that postulate silica molecules as primary growth units and nonclassical pathways (3D island growth) based on the aggregation of metastable silica nanoparticle precursors. And the low synthesis temperature $\left(80^{\circ} \mathrm{C}\right)$ yielded rounded (i.e., nonfaceted) crystals with roughened surfaces via a nonclassical route involving the direct attachment of nanoparticles. Wang et al. ${ }^{34}$ reported that high-silica nano ZSM-5 also could form ellipsoidal microsphere via a "nucleation/growth/aggregation" mechanism by a steam-assisted dry gel conversion. Here, with the presence of CNTs template, the crystallization process was significantly altered, presumably due to the change of local growth environmental induced by CNTs cage. Based on the SEM characterization of crystallization process (Fig. 4 and 5), we proposed an evolution mechanism of ZSM-5 microspheres with hierarchical structure (Scheme 1). During the crystallization, the CNT cage had an affinity potential towards aluminosilicate and silica precursors. When the hydrothermal pretreatment was carried out in a high $\mathrm{Al}$ precursor solution $(\mathrm{Si} / \mathrm{Al}$ ratio $<40)$, the concentration of aluminosilicate precursors in the CNTs cage was high enough to transform into the metastable species, aluminosilicates nanoparticles. The crystal growth became more prone to proceed by a nonclassical 3D island growth mechanism involving the direct attachment of nanoparticles, yielding spheroidal (i.e. nonfaceted) crystal with rough surface (Fig. 3 to 5). But in the low Al precursor solution ( $\mathrm{Si} / \mathrm{Al}$ ratio > 40), the CNT cage was prone to adsorb more silica precursor, which restrained the formation of aluminosilicates nanoparticles. Moreover, the low Al-doping contents could increase the crystallization rate by decreasing crystallization barrier. ${ }^{35}$ Therefore, the molecular addition became the predominant mechanism involving 2D layer nucleation and stepwise advancement of layers, which produced faceted ZSM- 5 crystals (Fig. 3c). In addition, as shown in Fig. 3b, the crystallization for ZSM-5 40 sample presented a mix mechanism of classical 2D layer growth and nonclassical 3D island growth in presence of CNTs template due to the middle content of Al content.

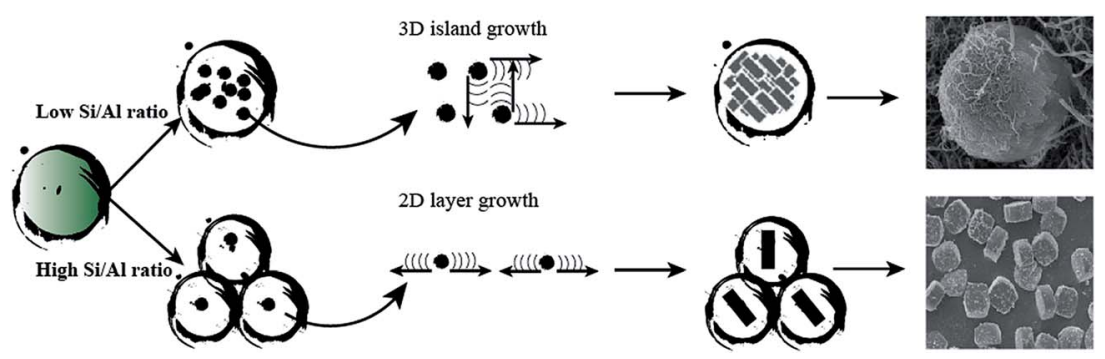

Scheme 1 Schematic illustration of the ZSM-5 microspheres formation during crystallization. 


\subsection{Catalytic hydroconversion of soybean oil}

The hydroconversion of soybean oil over series NiMo supported catalysts were investigated and the results are shown in Fig. 6 and 7 . In the hydroprocessing, the triglycerides and fatty acids in soybean oils underwent different deoxygenation reactions, releasing $\mathrm{CO}, \mathrm{CO}_{2}$ and $\mathrm{H}_{2} \mathrm{O}$, to yield the hydrocarbons over
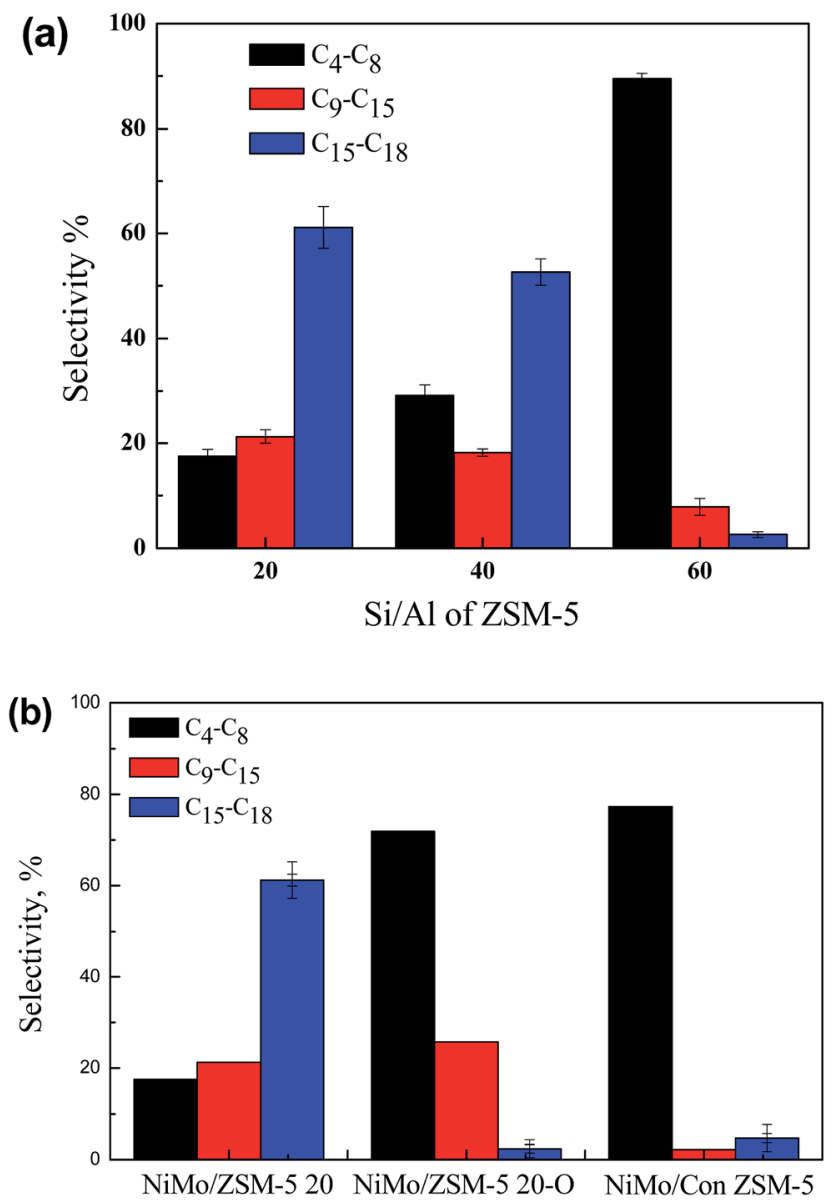

Fig. 6 Selectivity of different product fractions over (a) the ZSM-520, 40, 60 supported NiMo catalysts and (b) the ZSM-5 20 and ZSM-520$\mathrm{O}$ supported NiMo catalysts at $380{ }^{\circ} \mathrm{C}$.
NiMo active sites on the catalysts. ${ }^{36}$ The support had a very significant influence on the cracking of the deoxidated products, $\mathrm{C}_{17}$ and $\mathrm{C}_{18}$, to produce hydrocarbons from gasoline to diesel compounds. Fig. 6a shows the products distribution over NiMo/ZSM-5 20, NiMo/ZSM-5 40, and NiMo/ZSM-5 60 catalysts under the same reaction condition (at $380^{\circ} \mathrm{C}$ under $3 \mathrm{MPa}$ with $\mathrm{H}_{2}$ flow of $400 \mathrm{~mL} \mathrm{~min}^{-1}$ ). The selectivity of diesel-like hydrocarbons $\left(\mathrm{C}_{16}-\mathrm{C}_{18}\right)$ and aviation-like hydrocarbons $\left(\mathrm{C}_{9}-\mathrm{C}_{15}\right)$ increased with the decrease of $\mathrm{Si} / \mathrm{Al}$ ratio in $\mathrm{ZSM}-5$ zeolite, but the gasoline-like hydrocarbons $\left(\mathrm{C}_{4}-\mathrm{C}_{8}\right)$ had an opposite trend. The selectivity for $\mathrm{C}_{4}-\mathrm{C}_{8}, \mathrm{C}_{9}-\mathrm{C}_{15}$ and $\mathrm{C}_{16}-\mathrm{C}_{18}$ hydrocarbons over NiMo/ZSM-5 20 catalyst was $18 \%, 21 \%$ and $61 \%$, respectively, meanwhile it changed to $89 \%, 8 \%$ and $3 \%$ over the NiMo/ZSM-5 60 catalyst. The results indicated that the ZSM- 5 microsphere as the support had a great potential for the cracking inhibition to produce the $\mathrm{C}_{9}-\mathrm{C}_{15}$ and $\mathrm{C}_{16}-\mathrm{C}_{18}$ hydrocarbons from vegetable oil. Thus the cracking reactions would be restrained to a low level over the hierarchical ZSM-5 samples due to the faster diffusion through the secondary mesoporosity of the primary oil cracking products. ${ }^{19}$ In addition, the reduction of the ZSM-5 particle size led to a higher external surface area and low diffusion limitation to inhibit the deep cracking of hydrocarbons. ${ }^{37,38}$ As a comparison, the conventional microporous ZSM5 (Con ZSM-5, Si/Al = 25) and hierarchical ZSM-5 20-O zeolites were also evaluated for the hydroconversion of soybean oils. The NiMo/ZSM-5 20 catalyst (CNT as template) and the NiMo/ZSM-5 20-O catalyst (ODAC as template) showed the opposite products distribution. Obviously, the products over the NiMo/ZSM-5 20 catalyst were dominated by $\mathrm{C}_{16}-\mathrm{C}_{18}$ hydrocarbons (61\%), suggesting that only mild cracking occurred over this catalyst. While for the NiMo/ZSM-5 20-O catalyst, the deoxygenated products were almost cracked into $\mathrm{C}_{4}-\mathrm{C}_{8}$ hydrocarbons $(72 \%)$. Therefore, the hierarchical microspheres with both intra-crystal and inter-crystal mesopore and aggregated nanocrystal improved the mass transfer to exhibit highly selective cracking for jet fuel-ranged hydrocarbons. This result showed that the mesoporous template, CNT and ODAC, influenced the catalytic activity significantly by changing the structure of ZSM-5. As shown in Fig. 6b, the NiMo/Con ZSM-5 and the NiMo/ZSM-5 20$\mathrm{O}$ catalysts showed the similar product distribution with the NiMo/ZSM-5 60 catalyst. $77 \%$ and $72 \%$ selectivity of $\mathrm{C}_{4}-\mathrm{C}_{8}$
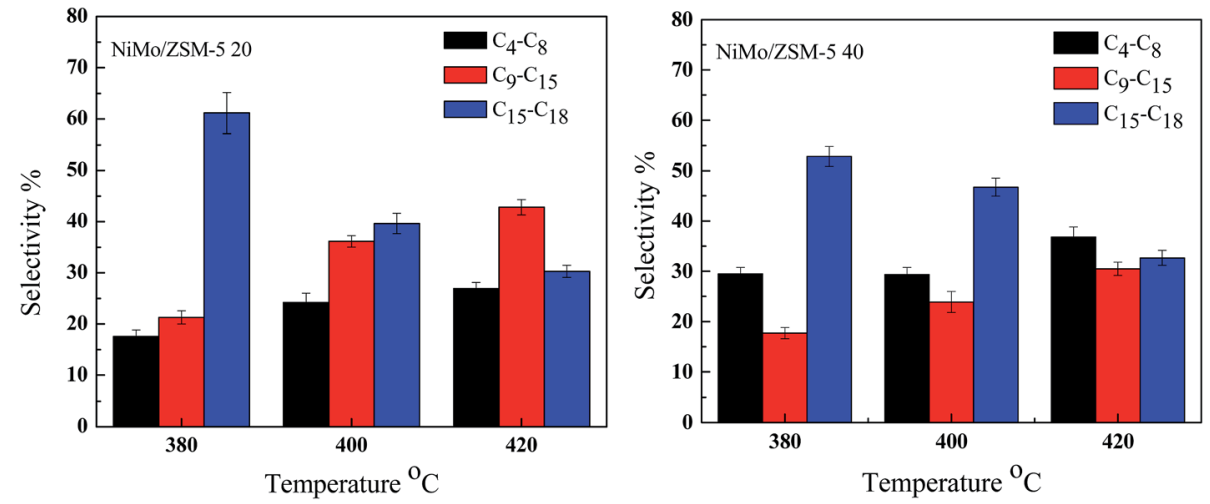

Fig. 7 Selectivity of different product fractions over the hierarchical ZSM-5 microspheres supported NiMo catalysts at different temperature. 
hydrocarbons were obtained over the NiMo/Con ZSM-5 and NiMo/ZSM-5 20-O samples, respectively, indicating that the hydrocarbons derived from deoxygenation of soybean oil were deeply cracked into gasoline range fraction. Compared the results over the NiMo/Con ZSM-5 and NiMo/ZSM-5 60 catalysts, it can be found that the hydroconversion of triglycerides under experimental conditions was almost same although the intracrystalline mesopores was introduced. This was also proved by the result over the NiMo/ZSM-5 20-O catalyst. The ZSM-5 20-O sample showed the similiar size distribution of mesopores with the ZSM-5 20, 40 and 60 samples (Fig. 2).

It was found that the ZSM-5 20 and ZSM-5 40 zeolites had uniform size $(2-3 \mu \mathrm{m})$ with the hierarchical structure containing intracrystalline and intercrystalline mesopore. While the ZSM-5 60 and ZSM-5 20-O zeolites showed the hierarchical structure containing only intercrystalline mesopore and the particle size of ZSM-5 20-O zeolite was much larger than that of the ZSM-5 60 zeolite. But the product distributions over ZSM-5 60 and ZSM-5 20-O were very close to the Con ZSM-5, which only had the micropores. These further indicated that the hierarchical with only intercrystalline mesopore in ZSM-5 zeolite contributed little to the production of aviation fuel range hydrocarbons $\left(\mathrm{C}_{9}-\mathrm{C}_{15}\right)$. And the hierarchical microsphere containing intracrystalline and intercrystalline mesopore enhanced the mass transfer and had a promising potential to inhibited the over cracking and produce the $\mathrm{C}_{9}-\mathrm{C}_{15}$ hydrocarbons.

Beside the commercial ZSM-5 zeolite, we also have investigated other typical commercial catalysts under the same conditions in our previous work such as $\mathrm{NiMo} / \mathrm{Al}_{2} \mathrm{O}_{3},{ }^{39} \mathrm{NiW} /$ $\mathrm{SiO}_{2}-\mathrm{Al}_{2} \mathrm{O}_{3}$ (ref. 40 and 41) and NiMo supported on hierarchical ZSM-5 treated by $\mathrm{NaOH} .{ }^{9,36}$ However, these catalysts did not showed high performance on the production of aviation fuels like hydrocarbons due to the conventional morphology and structure. This further suggested that the microsphere catalysts synthesized in this work exhibited a high potential for aviation fuel-like hydrocarbons production from hydroconversion of soybean oil.

It was accepted that the hydroconversion of triglycerides involves (a) hydrogenation of olefin double bonds, (b) hydrogenolysis of saturated triglycerides to fatty acids and propane, (c) HDO, DCO or $\mathrm{DCO}_{2}$ of fatty acids to alkanes and (d) cracking of the alkanes on the acid site in catalyst. ${ }^{42}$ The cracking was mainly depended on the catalysts and the reaction temperature. In order to further verify the selective cracking performance for $\mathrm{C}_{9}-\mathrm{C}_{15}$ hydrocarbons over the micropherical NiMo/ZMS-5 20 catalyst, the hydrodeoxygenation of soybean oils was also carried out at higher temperatures (Fig. 7). Because that the conventions of triglycerides were very low when experiments were done below $380{ }^{\circ} \mathrm{C}$ and the cracking became seriously when the temperature was higher than $420{ }^{\circ} \mathrm{C}$ from the results we obtained and already published using Ni-Mo supported on hierarchical ZSM-5 catalysts. ${ }^{20}$ Therefore, the catalytic performance for all the catalysts were compared in the range of 380$420{ }^{\circ} \mathrm{C}$. Compared with the NiMo/ZSM-5 40 catalyst, the micropherical NiMo/ZSM-5 20 catalyst also showed significant enhancement of the $\mathrm{C}_{9}-\mathrm{C}_{15}$ selectivity. The selectivity of $\mathrm{C}_{9}-\mathrm{C}_{15}$ hydrocarbons increased from $21.3 \%$ up to $42.8 \%$ and was also much higher than that of $\mathrm{C}_{4}-\mathrm{C}_{8}$ hydrocarbons over the NiMo/ ZSM-5 20 catalyst. But as for the NiMo/ZSM-5 40 catalyst, the selectivity of $\mathrm{C}_{9}-\mathrm{C}_{15}$ hydrocarbons (17.7-30.5\%) was lower than that of $\mathrm{C}_{4}-\mathrm{C}_{8}$ hydrocarbons (29.4-36.8\%). These results further proved that the microsphere ZSM-5 zeolite could provide a more favourable hierarchical structure for selective cracking to produce $\mathrm{C}_{9}-\mathrm{C}_{15}$ hydrocarbons in the hydrodeoxygenation of vegetable oil.

\section{Conclusions}

In this work, a simple ZSM-5 synthetic method that controls the shape and size via hydrothermal crystallization using CNTs as template was developed. The effects of $\mathrm{Si} / \mathrm{Al}$ ratio and addition of CNTs in the synthesis system on the shape evolution of ZSM-5 morphology were investigated. Aggregated hierarchical ZSM-5 microspheres composed of small ZSM-5 granules were prepared in low $\mathrm{Si} / \mathrm{Al}$ ratio. While in high $\mathrm{Si} / \mathrm{Al}$ ratio the "classicboat" ZSM-5 samples with obvious mesopores in the framework were obtained. The presence of CNTs acted as a mesopore template and also provide the limited synthesis space to control the growth of ZSM-5 crystal. The high hydrothermal temperature $\left(175{ }^{\circ} \mathrm{C}\right)$ made the precursor particles grow faster in the CNTs environment, while the CNTs acted as a cage to promote the precursor crystals aggregating together to grow. A 3D island growth mechanism of ZSM-5 microsphere was proposed. The obtained ZSM-5 microspheres had the uniform size $(2-3 \mu \mathrm{m})$ with the hierarchical structure of intra-crystal and inter-crystal mesopore. The ZSM-5 microsphere supported NiMo catalysts exhibited a high potential for aviation fuel-like hydrocarbons production $\left(42.8 \%\right.$ selectivity of $\mathrm{C}_{9}-\mathrm{C}_{15}$ hydrocarbons over NiMo/ZSM-5 20) from hydroconversion of soybean oil.

\section{Conflicts of interest}

There are no conflicts to declare.

\section{Acknowledgements}

Financial supports from the National Natural Science Foundation of China (Grant No. 21476169, 21476168) are gratefully acknowledged.

\section{References}

1 S. K. Kim, S. Brand, H. Lee, Y. Kim and J. Kim, Chem. Eng. J., 2013, 228, 114.

2 A. Corma, Chem. Rev., 1997, 97, 2373.

3 K. Zhao, Y. Cheng, H. Liu, C. Yang, L. Qiu, G. Zeng and H. He, RSC Adv., 2015, 5, 66013.

4 L. Qiu, Y. Cheng, C. Yang, G. Zeng, Z. Long, S. Wei, K. Zhao and L. Luo, RSC Adv., 2016, 6, 17036.

5 S. Wei, H. He, Y. Cheng, C. Yang, G. Zeng and L. Qiu, RSC $A d v .$, 2016, 6, 103253.

6 S. Wei, H. He, Y. Cheng, C. Yang, G. Zeng, L. Kang, H. Qian and C. Zhu, Fuel, 2017, 200, 11. 
7 A. Corma, Chem. Rev., 1995, 95, 559.

8 T. Armaroli, L. Simon, M. Digne, T. Montanari, M. Bevilacqua, V. Valtchev, J. Patarin and G. Busca, Appl. Catal., A, 2006, 306, 78.

9 H. Chen, Q. Wang, X. Zhang and L. Wang, Ind. Eng. Chem. Res., 2014, 53, 19916.

10 J. Perez-Ramirez, C. H. Christensen, K. Egeblad and J. C. Groen, Chem. Soc. Rev., 2008, 37, 2530.

11 D. P. Serrano, J. M. Escola and P. Pizarro, Chem. Soc. Rev., 2013, 42, 4004.

12 C. M. Parlett, K. Wilson and A. F. Lee, Chem. Soc. Rev., 2013, 42, 3876.

13 P. Bai, P. Wu, W. Xing, D. Liu, L. Zhao, Y. Wang, B. Xu, Z. Yan and X. S. Zhao, J. Mater. Chem. A, 2015, 3, 18586.

14 J. Pérez-Ramírez, D. Verboekend, A. Bonilla and S. Abelló, Adv. Funct. Mater., 2009, 19, 3972.

15 J. C. Groen, L. A. Peffer, J. A. Moulijn and J. Pérez-Ramírez, Chem.-Eur. J., 2005, 11, 4983.

16 J. Pérez-Ramírez, S. Abelló, A. Bonilla and J. C. Groen, Adv. Funct. Mater., 2009, 19, 164.

17 S. J. You and E. D. Park, Microporous Mesoporous Mater., 2014, 186, 121.

18 M. Choi, K. Na, J. Kim, Y. Sakamoto, O. Terasaki and R. Ryoo, Nature, 2009, 461, 246.

19 J. A. Botas, D. P. Serrano, A. García and R. Ramos, Appl. Catal., B, 2014, 145, 205.

20 D. Verma, R. Kumar, B. S. Rana and A. K. Sinha, Energy Environ. Sci., 2011, 4, 1667.

21 S. Sartipi, K. Parashar, M. J. Valero-Romero, V. P. Santos, B. van der Linden, M. Makkee, F. Kapteijn and J. Gascon, J. Catal., 2013, 305, 179.

22 J. Kang, K. Cheng, L. Zhang, Q. Zhang, J. Ding, W. Hua, Y. Lou, Q. Zhai and Y. Wang, Angew. Chem., Int. Ed., 2011, 50, 5306.

23 J. Bao, J. He, Y. Zhang, Y. Yoneyama and N. A. Tsubaki, Angew. Chem., Int. Ed., 2008, 120, 359.

24 M. Choi, Z. Wu and E. Iglesia, J. Am. Chem. Soc., 2010, 132, 9129.
25 X. Qian, J. Du, B. Li, M. Si, Y. Yang, Y. Hu, G. Niu, Y. Zhang, H. Xu, B. Tu, Y. Tang and D. Zhao, Chem. Sci., 2011, 2, 2006.

26 B. Li, B. Sun, X. Qian, W. Li, Z. Wu, Z. Sun, M. Qiao, M. Duke and D. Zhao, J. Am. Chem. Soc., 2013, 135, 1181.

27 T. Ennaert, J. Van Aelst, J. Dijkmans, R. De Clercq, W. Schutyser, M. Dusselier, D. Verboekend and B. F. Sels, Chem. Soc. Rev., 2016, 45, 584.

28 J. Pérez-Ramírez, C. H. Christensen, K. Egeblad, C. H. Christensen and J. C. Groen, Chem. Soc. Rev., 2008, $37,2530$.

29 M. H. M. Ahmed, O. Muraza, A. M. Al-Amer and Z. H. Yamani, Microporous Mesoporous Mater., 2016, 227, 48.

30 H. Tao, H. Yang, X. Liu, J. Ren, Y. Wang and G. Lu, Chem. Eng. J., 2013, 225, 686.

31 L. Shirazi, E. Jamshidi and M. R. Ghasemi, Cryst. Res. Technol., 2008, 43, 1300.

32 N. Ren, B. Subotić, J. Bronić, Y. Tang, M. Dutour Sikirić, T. Mišić, V. Svetličić, S. Bosnar and T. Antonić Jelić, Chem. Mater., 2012, 24, 1726.

33 A. I. Lupulescu and J. D. Rimer, Science, 2014, 344, 729.

34 H. Li, Y. Wang, F. Meng, H. Chen, C. Sun and S. Wang, RSC Adv., 2016, 6, 99129.

35 Z. Hu, H. Zhang, L. Wang, H. Zhang, Y. Zhang, H. Xu, W. Shen and Y. Tang, Catal. Sci. Technol., 2014, 4, 2891.

36 H. Chen, Q. Wang, X. Zhang and L. Wang, Appl. Catal., B, 2015, 166-167, 327.

37 I. Schmidt, C. Madsen and C. J. H. Jacobsen, Inorg. Chem., 2000, 39, 2279.

38 R. O. Idem, S. P. R. Katikaneni and N. N. Bakhshi, Fuel Process. Technol., 1997, 51, 101.

39 H. Chen, Q. Wang, X. Zhang and L. Wang, Fuel, 2015, 159, 430.

40 Y. Yang, Q. Wang, H. Chen and X. Zhang, Fuel, 2014, 133, 241.

41 Y. Yang, Q. Wang, X. Zhang, L. Wang and G. Li, Fuel Process. Technol., 2013, 116, 165.

42 C. Zhao, T. Brückb and J. A. Lercher, Green Chem., 2013, 15, 1720. 